\title{
Effect of Acid Type on Si-K-HAs Gel Characterization
}

\author{
Srie Muljani ${ }^{1}$, Bambang Wahyudi \\ Chemical Engineering Department \\ Universitas Pembangunan Nasional "Veteran" Jawa Timur \\ Surabaya, Indonesia \\ ${ }^{1}$ sriemuljani.tk@upnjatim.ac.id
}

\begin{abstract}
The effect of both citric acid and hydrochloric acid on the Si-K-HAs gel characterization was studied with various pH gelation. The Si-K-HAs gel obtained from acidification of the mixture of potassium silicate and potassiumhumic substance solution by polymerization process. The humic substance was obtained from peat extraction while silica obtained from geothermal sludge extraction, both using potassium hydroxide solution as solvent. The volume ratio of potassium silicate to humic substance solution studied in the range of $1: 1$, 1:2, 1:5 dan 1:10. The Si-K-HAs gel dried and powdered samples were characterized by IR spectra, X-ray diffraction, and SEMEDX. The different of type of acid caused the composition and characteristic of Si-K-HAs on product also difference.
\end{abstract} acid

Keywords- potassium silicate; humic substance; gel; citric

\section{INTRODUCTION}

Silica gel formation has been known to be carried out either from sodium silicate or from TEOS by the polycondensation, precipitation, and sol gel method [1]. Gorrepati et al [2] reported that the precipitation of silica products from acid dissolution of minerals can studied apart from the mineral dissolutuion process. The silica product precipitation from mineral acidification follows a two-step process, formation of primary particles followed by particle floculation which becomes exponentially faster with increasing $\mathrm{HCl}$ concentration and with salts accelerating the process in the above order. The use of organic acids for acidification can increase particle size and surface area of silica gel compared to the particle size of silica gel prepared by inorganic acids [3]. The study of silica-based composites has also been developed by several researchers to obtain the new materials silica-based composites [4;5;6]. While a large number of different synthesis approaches for the preparation of mesophorous silica polymer nanocomposite has been reported in literature $[7 ; 8]$.

This study develops the formation of a gel matrix between silica, humic acid and potassium by studying the effect of acid types in the acidification process. In the previous study, the synthesis of matrix silica-potassium-humic subatances ( $\mathrm{Si}-\mathrm{K}$ HAs) gel has been prepared by gradual extraction and acidification by citric acid in the range of 1-3N [9]. This study performed by simultaneous extraction, while the potassium silicate and potassium-humic substance solution was mixture for acidification process. Alexander et al [10] reported that immobilizing silanized humic derivatives onto silica gel in aquatic solutions. The silanized humic derivatives obtained without a use of organic solvent by reacting natural humic materials from peat and coal with 3-aminopropyl triethoxyorganosilane in water. The type of organic acid for acidification also needs to be considered with the number of different carbon chains. Gelation $\mathrm{pH}$ is critical for determining the silica gel quality [2;3]. Meanwhile the presence of humic acid which contains a lot of carbon is may also a consideration in its effect on the Si-K-HA gel matrix formation [11].

Extraction of humic acid from peat generally uses sodium hydroxide as a solvent $[12 ; 13]$. This study uses potassium hydroxide in addition to the extraction of silica from geothermal sludge as well as for the extraction of humic acid from peat. The use of potassium hydroxide as a solvent is intended so that the gel product contains potassium. Potassium humate is a good source of humic acid. Its stimulation to plant growth is a function of nutrients supply to the plant. A clear significantly positive trend was seen in increasing plant height, stem diameter and root length by increasing the concentration of potassium humate [14]. Likewise, potassium silicate which is a new fertilizer material involved silica and potassium elements which has been commercialized $[15 ; 16]$. The Si-KHA gel product developed in this study is a combination of potassium humate and potassium silicate in a composite with a controlled of $\mathrm{pH}$ and composition.

\section{MATERIAL AND METHODS}

\section{A. Materials}

Geothermal sludge as a source of silica amorphous is a solid waste of geothermal plant obtained from Dieng, Wonosobo, Indonesia. Geothermal sludge contain about 87-91 $\mathrm{w} \% \mathrm{SiO}_{2}$ from the result of $\mathrm{X}$-ray fluorescence analysis. Peats obtained from Banjarmasin Kalimantan Indonesia. The chemicals $\mathrm{KOH}$ pa and Citric acid obtained from CV Vanjaya Medica Surabaya, Indonesia.

\section{B. Methodology}

Fig.1, showed the procedure experiment to produced SiK-HAs gel by acidification method. Preparation of Si-K-HA 
solution was started with the extraction process stage, 1) the extraction of silica from $300 \mathrm{~g}$ of geothermal sludge using $1200 \mathrm{ml}$ of $\mathrm{KOH} 3 \mathrm{~N}$ solution at $100{ }^{\circ} \mathrm{C}$ by heating stirrer plate to obtain about $1000 \mathrm{ml}$ of potassium silicate solution. Silica $\left(\mathrm{Si}_{2} \mathrm{O}\right)$ concentration in potassium silicate solution was obtained at $18.5 \%$ and potassium concentration $\left(\mathrm{K}_{2} \mathrm{O}\right)$ was $12.7 \%$. 2) humic acid was extracted from 100 grams of peat using $1000 \mathrm{ml}$ of $3 \mathrm{~N} \mathrm{KOH}$ solution. Potassium silicate solution was mixed with potassium humic solution in volume ratio $1: 1,1: 2,1: 5$ and 1:10. The total mixture of potassium humic solution and potassium silica solution is $300 \mathrm{ml}$. The solution mixture was then titrated using citric acid or $\mathrm{HCl} 2 \mathrm{~N}$ until it reaches the final $\mathrm{pH}$ value of 7 and 10 respectively. The next step is aging for $48 \mathrm{~h}$ until the appearance of uniform density. The solid gel is then dried in an oven for $24 \mathrm{~h}$ at $100^{\circ}$ C. The dry gel was grounded into powder for analysis purposes.

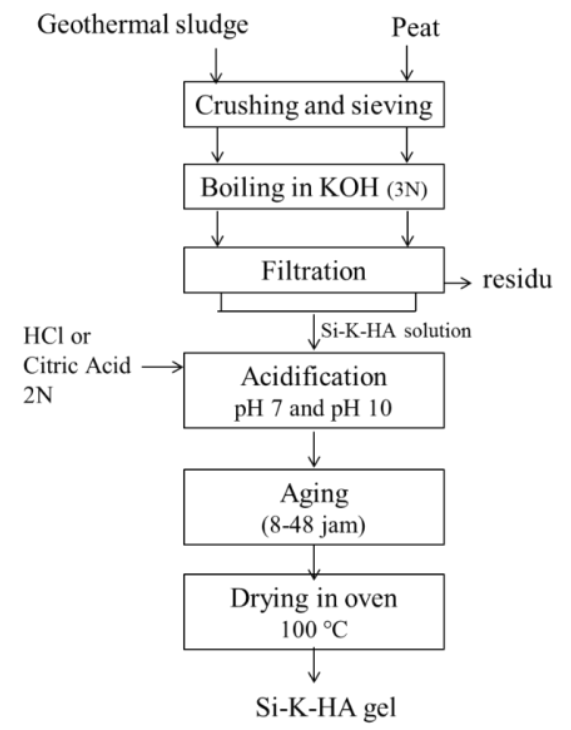

Fig.1. Diagram procedure of experiment Si-K-HAs gel production

\section{Charcterization}

The characteristics of Si-K-HA gel products were carried out by X-ray diffraction, IR spectra of FTIR, and SEM-EDX.

\section{RESUlt AND DISCUSSION}

\section{A. Effect of ratio volume ( $\mathrm{K}$-Has/K-SiO2) on compositon of Si-K-HAs product}

Table 1. Showed the composition of Si-K-HA products at a volume ratio of 1: 1 to 1: 5 resulted from EDX analysis at magnification of 10,000 . The ratio volume of $1: 1$ produced $\mathrm{Si}$ K-HA prepared by citric acid and $\mathrm{HCl}$ with ratio of $30.2 / 11.7$ and $19.7 / 18.7$ of $\mathrm{Si} / \mathrm{K}$ respectively. In the volume ratio $1: 2$, produced the $\mathrm{Si}-\mathrm{K}-\mathrm{HA}$ with $\mathrm{Si} / \mathrm{K}$ ratio of $26.7 / 10.3$ and $28.2 / 19.6$. While in volume ratio $1: 5$ produced $\mathrm{Si} / \mathrm{K}$ ratios of 27.7/0.6 and 24.4/20 respectively. The mixture composition obtained the variation of $\mathrm{Si} / \mathrm{K}$ ratio in $\mathrm{Si}-\mathrm{K}-\mathrm{HA}$ products. At a volume ratio of 1: 5 the amount of potassium humic solution is much smaller than potassium silicate solution. The product of
Si-K-HA prepared by citric acid causes the potassium element to be smaller, but the silica element remains stable from the volume ratio 1: 1 to 1:5. However, the presence of $\mathrm{Cl}$ element in the $\mathrm{Si}-\mathrm{H}-\mathrm{KA}$ product prepared by $\mathrm{HCl}$ is less acceptable if it will be used as fertilizer. Conversely, citrate can support the degradation of heavy metals, especially aluminum in the soil. The presence of citrate groups can be indicated using IR spectra.

\section{TABLE I. THE COMPOSITION OF SI-K-HA PRODUCTS}

\begin{tabular}{|c|c|c|c|c|c|c|}
\hline Vol.Ratio & \multicolumn{2}{|c|}{$1: 5$} & \multicolumn{2}{c|}{$1: 2$} & \multicolumn{2}{c|}{$1: 1$} \\
\hline Comp & HCl & Citric & HCl & Citric & HCl & Citric \\
\hline $\mathrm{C}$ & 04.95 & 13.40 & 08.03 & 18.66 & 09.05 & 16.01 \\
\hline $\mathrm{O}$ & 31.34 & 41.22 & 19.91 & 42.60 & 22.69 & 41.13 \\
\hline $\mathrm{Si}$ & 24.43 & 27.72 & 28.22 & 26.70 & 19.75 & 30.21 \\
\hline $\mathrm{K}$ & 20.51 & 06.47 & 19.63 & 10.37 & 18.74 & 11.72 \\
\hline $\mathrm{Cl}$ & 18.26 & - & 24.21 & - & 29.76 & - \\
\hline
\end{tabular}

Figure 2 showed the morphology of Si-K-HA prepared by a) citric acid and b) $\mathrm{HCl}$ in volume ratio 1:5. The Si-K-HA particle size was prepared by $\mathrm{HCl}$ higher than $\mathrm{Si}-\mathrm{K}-\mathrm{HA}$ particle size prepared by citric acid. Both products have a nonuniform particle size. Figure $3 a$ and $3 b$ showed the morphology of Si-K-HA prepared by citric acid and $\mathrm{HCl}$ in volume ratio of 1:1 respectively. Si-K-HA products prepared by a volume ratio of 1: 1 appear to be more fused between one particle and another, and also more uniform than silica prepared by a volume ratio of $1: 5$. This may be due to more opportunities to form polymer bonds between silica and humic acid.
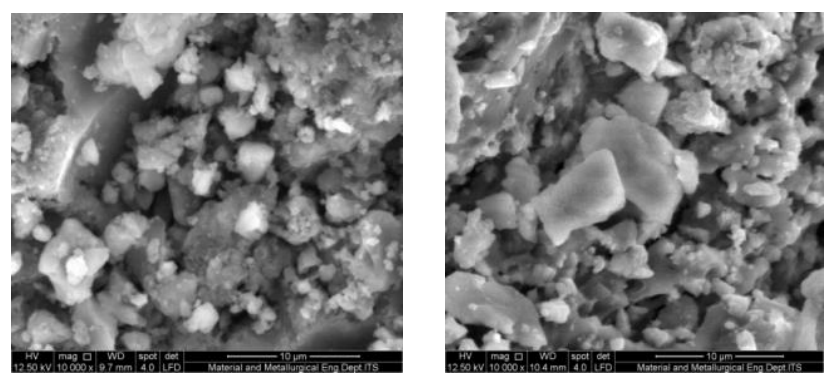

Fig.2. Morphology of Si-K-HAs particles prepared by a) citric acid and b) $\mathrm{HCl}$ in volume ratio 1:5
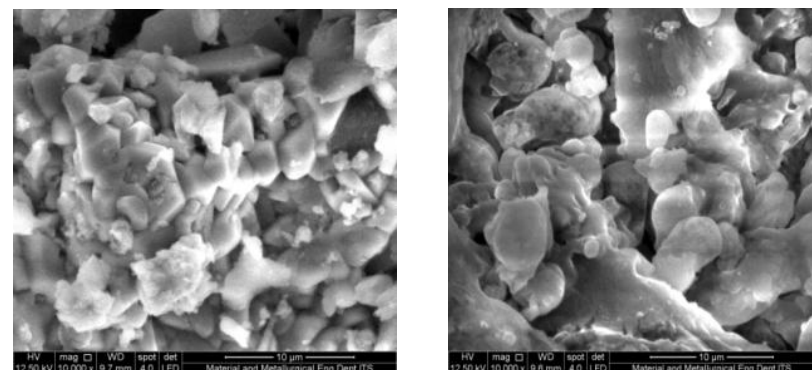

Fig.3. Morphology of Si-K-HAs particles prepared by a) citric acid and b) $\mathrm{HCl}$ in volume ratio $1: 1$

Fig. 4 showed the split of IR spectra of $\mathrm{Si}-\mathrm{K}-\mathrm{HAs}$ product prepared by a) $\mathrm{HCl}$ and b) citric acid. A peak of about 3432 $\mathrm{cm}^{-1}$ wavenumber appears which indicates the presence of 
alcohol $(\mathrm{O}-\mathrm{H})$ or phenol monomers which sometimes change (Fig. 2a), while the use of citric acid indicates the presence of carboxylic monomers with moderate intensity at waves of about 3400 and $3260 \mathrm{~cm}-1$ (Fig 2b). The greater the volume ratio from 1: 1 to 1:10 causes the lower peak of alcohol groups and carboxylic groups to almost disappear.

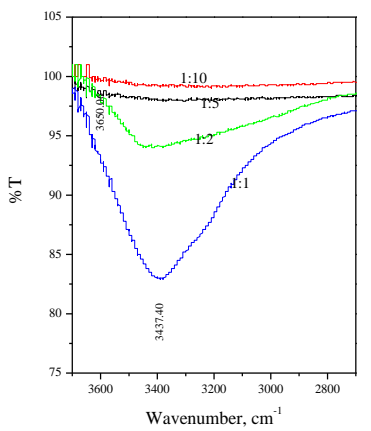

(a1)

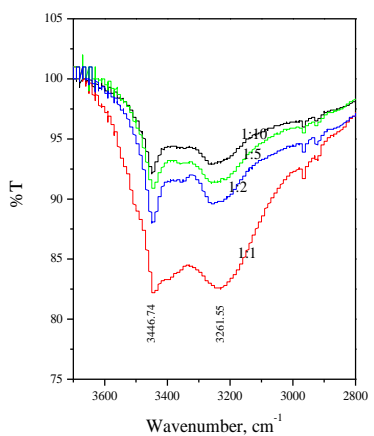

(b1)

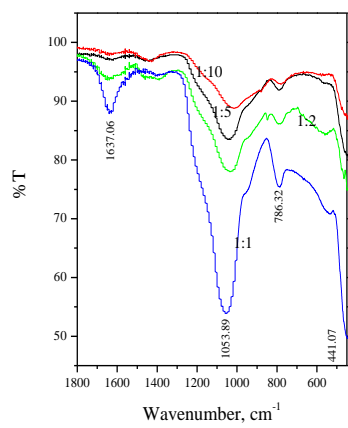

(a2)

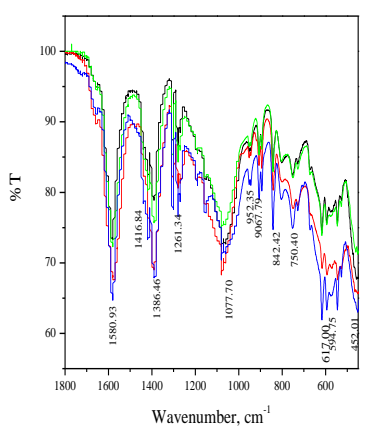

(b2)
Fig. 4. The split of IR spectra of Si-K-HAs particles prepared by a) $\mathrm{HCl}$ and b) citric acid

In the range of wavenumbers 1800 to $450 \mathrm{~cm}^{-1}$ it appears that the use of organic acids provides more R-COO-groups, resonance is possible between the two - $\mathrm{CO}$ groups. The characteristic hydrochloric acid group absorption around 1637 $\mathrm{cm}^{-1}$ (Fig.2c ) disappears and is replaced by two bands; the first occurs between $1580 \mathrm{~cm}^{-1}$ and the second in the 1410$1386 \mathrm{~cm}^{-1}$ region (Fig.2d). These absorptions correspond to the asymmetric and symmetric vibrations of the $\mathrm{R}-\mathrm{COO}^{-}$ group. Peak about $1716 \mathrm{~cm}^{-1}(\mathrm{C}=\mathrm{O}$ stretching of $\mathrm{COOH}$ and other carbonyl groups), whose relative intensity was determined only for $\mathrm{SH}$ from lignite [11]. Of these two bands, the band around $1600 \mathrm{~cm}^{-1}$ is most indicative since the symmetric absorption occurs in the crowded fingerprint region. The Silanol group ( $\mathrm{Si}-\mathrm{O}-\mathrm{Si}$ ) is a characteristic strong band centered around $1100 \mathrm{~cm}^{-1}$ which sometimes appears as one band and in other samples as multiple bands, the bands due to associated water molecules around $3400 \mathrm{~cm}^{-1}$ and 1640 $\mathrm{cm}^{-1}$. Wavenumber about $1045-041 \mathrm{~cm}^{-1}(\mathrm{C}-\mathrm{O}$ stretching of polysaccharides or polysaccharide-like substances, and $\mathrm{Si}-\mathrm{O}$ of silicate impurities) [11].

\section{B. Effect of type acid on IR-spectra Si-K-HAs characterization}

The acidification process of Si-K-HAs gel formation using either citric acid or $\mathrm{HCl}$ was stopped until it reached two sets of $\mathrm{pH}$ values of 7 and 10. Figure 4 showed IR spectra of Si-KHAs prepared a) at $\mathrm{pH} 7$ and b) at $\mathrm{pH} 10$. At both $\mathrm{pH}$ IR spectra of Si-K-HAs particles showed the same tendency at each position and peak at wave numbers 4000 to $450 \mathrm{~cm}-1$

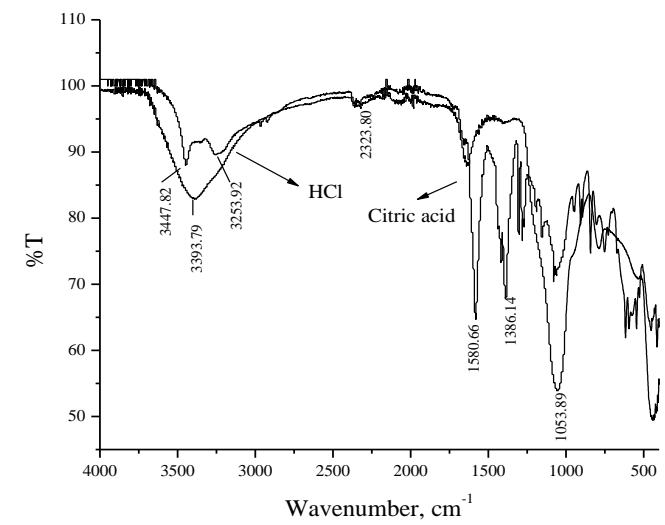

(a)

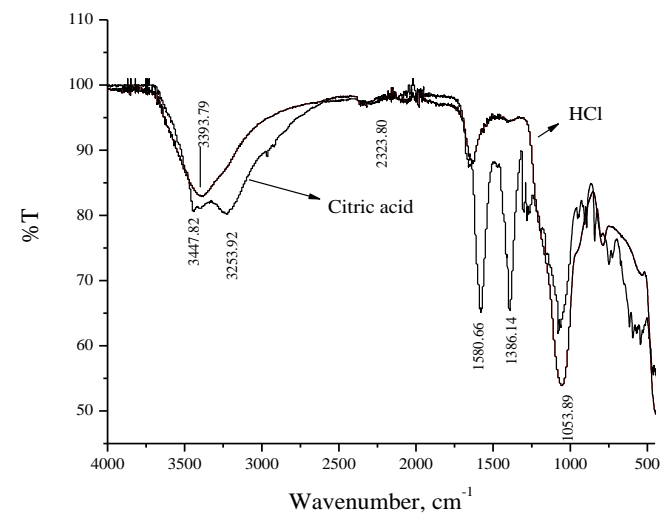

(b)

Figure 5 IR spectra of Si-K-HAs prepared a) at $\mathrm{pH} 7$ and b) at $\mathrm{pH} 10$.

Potassium citrate groups appear in wavenumbers about 1580 and $1386 \mathrm{~cm}^{-1}$, while the potassium silicate group in wavenumber about $1053 \mathrm{~cm}^{-1}$. The characteristic asymmetric stretching absorption from the $\mathrm{CO}_{2}$ - group in the 1650-1550 $\mathrm{cm}^{-1}$ region as carboxylic acid salts typically. The corresponding symmetric stretching absorption occurs at around 1440-1335 $\mathrm{cm}^{-1}$. For acid salts with a strongly electronegative group the asymmetric stretching absorption will shift to higher frequencies around $1690 \mathrm{~cm}^{-1}$.

Figure 6 showed diffraction pattern of Si-K-HAs particles prepared by a) $\mathrm{HCl}$ and b) citric acid in the volume ratio $1: 1$. The diffraction pattern of Si-K-HAs particles prepared by citric acid and $\mathrm{HCl}$ both exhibit an amorphous crystal structure. The peak of the chloride salt appears to stand out at 
about 32 angles $2 \Theta$ (Fig. 6a) while the citric salt is at 10 angle $2 \Theta$ (Fig. 6b).

\section{Effect of type acid on structure Si-K-HAs characterization}

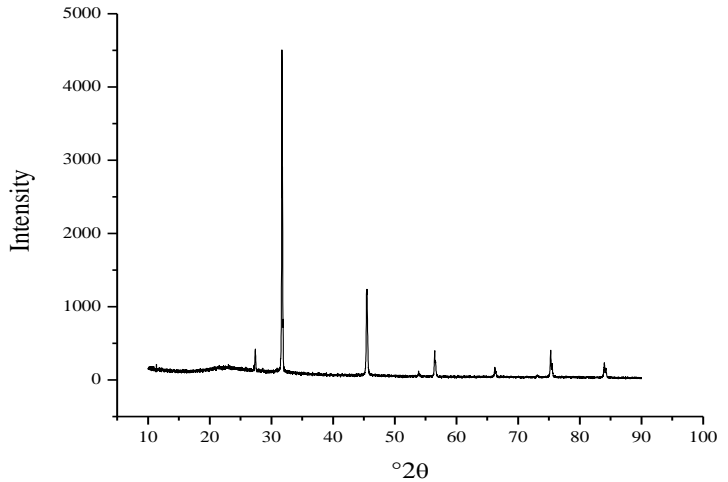

(a)

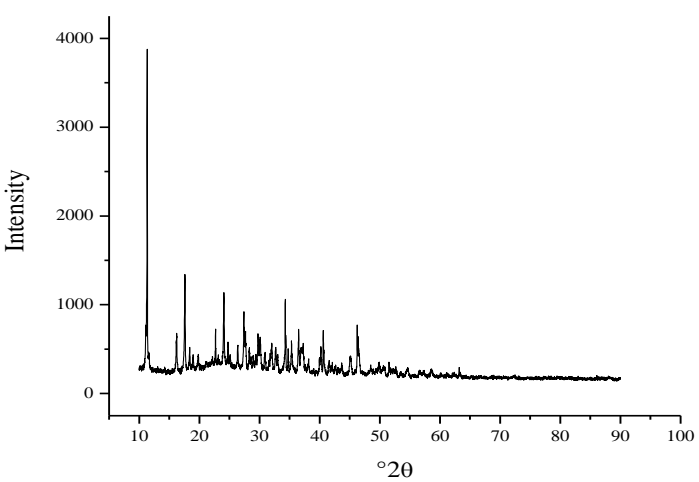

(b)

Fig. 6 Diffraction pattern of Si-K-HAs particles prepared by a) $\mathrm{HCl}$ and b) citric acid in the volume ratio of $1: 1$

\section{CONCLUSION}

Si-K-HAs composite materials have been successfully made from potassium humic and potassium silicate solutions by acidification process using citric acid and $\mathrm{HCl}$.

The volume ratio between potassium humic solution and potassium silicate solution gives a variety of $\mathrm{Si}-\mathrm{K}-\mathrm{HAs}$ product characteristics. But the results of the study on the volume ratio show that at the volume ratio 1: 1 the composition and morphology of the product are in line with expectations as fertilizer product.

Even though the Si-K-HAs products provided from $\mathrm{HCl}$ are more stable and solid, the presence of $\mathrm{Cl}$ elements that are too much is less expected especially for fertilizer needs. The $\mathrm{Si}-\mathrm{K}-\mathrm{HAs}$ gel formed is still less homogeneous between the silica and humic particles even though they form a gel simultaneously but some are still separated after drying, this appears from the white and brown colors which are not homogeneous.

\section{ACKNOWLEDGMENT}

The authors are grateful to the Ministry of Research and Technology Indonesia, for its financial support through Hibah Desentralisasi PTUPT 2018. We also thank PT Geodipa Energi for providing the geothermal sludge. Thanks to Ivan Atmanegara, Mardining, Titah Ariqoh and Indira Apsari for the assistance on this research.

\section{REFERENCES}

[1] C.J. Brinker, "Hydrolysis and condensation of silicates: Effects on structure". J. Non-Cryst Sol, 100, pp. 31-50, 1988

[2] E.A. Gorrepati, P. Wongthahan, P., S. Raha, H.S. Fogler, "Silica Precipitation in Acidic Solutions: Mechanism, $\mathrm{pH}$ Effect, and Salt Effect", Langmuir, 26 (13), pp. 10467-10474, 2010

[3] S. Muljani, H. Setyawan, G. Wibawa, and A. Altway, "A facile method for the production of high-surface-area mesoporous silica gels from geothermal sludge”, Adv. Pow.Tech., 25 (5), pp. 1593-1599, 2014

[4] D.W. Lee and B.R. Yoo, (2016) "Advanced silica/polymer composite: Materials and aplications", J. Ind and EngChem, 38, pp. 1-12, 2016

[5] M. Fujiwara,K. Shiokawa, Y.C. Zhu, "Preparation of mesoporous silica/polymersulfonate compositematerials", J. Mol. Catal. A, Chem, 264, pp. 153-161, 2007

[6] N. Misra, G.Kapusetti, D.K. Pattanayak, A. Kumar, "Fabrication and characterization of epoxy/silica functionally graded composite material", Indi. J. Phys, 85, 1393, 2011.

[7] S. Salimian, A. Zadhoush, A. Mohammadi, A review on new mesostructured composite materials: Part I. Synthesis of polymermesoporous silica nanocomposite, J. Reinf. Plas.Comp., 2018, Online ISSN: 1530-7964

[8] H. Zou, S.S. Wu, and J. Shen, "Polymer/silica nanocomposites, preparation, characterization, properties, and aplications", Chem. Rev, 108, pp. 3893-3957, 2008

[9] S. Muljani, Synthesis of matrix of SI-K-HAs gel from geothermal sludge and peat", Reaktor, vol 18, No.2, 2018

[10] B.V. Alexander, A.P. Sergey, I.K. Andrey, K.K. Hatfied, and I.V. Perminova, "Nature-like solution for removal of direct brown 1 azo dye from aqueous phase using humics-modified silica gel", Chemos, 145 , pp. 83-88, 2016

[11] V.Enev, P. Lubica, K. Martina, L. Tibor, and D. Leos, Spectral Characterization of Selected Humic Substances, Soil \& Water Res., 9 (1), pp. 9-17, 2014

[12] Saito, and M.M. Seckler, "Alkaline extraction of humic substances from peat applied to organic-mineral fertilizer production", Braz.J. ChemEng.,31 (3).2014

[13] W.M. Roger, Alkalated humic acid-silica compositions for fertilizers and the like and methods of making same, 1971, US 3552943A

[14] M. Ali, M. Azam, and M. Adnan, "Influence of Potassium Humate on Am Contamination and Rhizospheric Mycoflora of Rice (Oryza sativa L)" J. Bio.Agri.Health. 5, 1, 2015.

[15] G.B. Buck, H.K. Gaspar,A. Nolla, and L. Coelho, "Potassium silicates as foliar spray and rice blast control", J.Plant.Nutri., 31, pp 231-237, 2008

[16] S.Muljani, B. Wahyudi, K. Sumada, and Suprihatin "Potasium silicate foliar fertilizer grade from geothermal sludge and pyrophylite" MATEC Web of Conferences, 58, 2016, Les Ulis: EDP Sciences. 